\title{
Prevention of poststernotomy wound infections in obese patients by negative pressure wound therapy
}

\author{
Onnen Grauhan, MD, PhD, MBA, Artashes Navasardyan, Michael Hofmann, MD, Peter Müller,
} Julia Stein, MSc, and Roland Hetzer, MD, PhD

\begin{abstract}
Objective: The majority of wound infections after median sternotomy in obese patients are triggered by the breakdown of skin sutures and subsequent seepage of skin flora. The purpose of this study was to evaluate negative pressure wound dressing treatment for the prevention of infection. We hypothesized that negative pressure wound dressing treatment for 6 to 7 days applied immediately after skin closure reduces the numbers of wound infections.
\end{abstract}

\begin{abstract}
Methods: In a prospective study, 150 consecutive obese patients (body mass index $\geq 30$ ) with cardiac surgery performed via median sternotomy were analyzed. In the negative pressure wound dressing treatment group $(\mathrm{n}=75)$, a foam dressing (Prevena, KCI, Wiesbaden, Germany) was placed immediately after skin suturing, and negative pressure of $-125 \mathrm{~mm} \mathrm{Hg}$ was applied for 6 to 7 days. In the control group $(\mathrm{n}=75)$, conventional wound dressings were used. The primary end point was wound infection within 90 days. Mann-Whitney $U$ test and Fisher exact test were used. Freedom from infection was estimated by Kaplan-Meier analysis.
\end{abstract}

Results: Three of 75 patients $(4 \%)$ with continuous negative pressure wound dressing treatment had wound infections compared with 12 of 75 patients $(16 \%)$ with conventional sterile wound dressing $(P=.0266$; odds ratio, $4.57 ; 95 \%$ confidence interval, 1.23-16.94). Wound infections with Gram-positive skin flora were found in only 1 patient in the negative pressure wound dressing treatment group compared with 10 patients in the control group $(P=.0090$; odds ratio, $11.39 ; 95 \%$ confidence interval, 1.42-91.36).

Conclusions: Negative pressure wound dressing treatment over clean, closed incisions for the first 6 to 7 postoperative days significantly reduces the incidence of wound infection after median sternotomy in a high-risk group of obese patients. (J Thorac Cardiovasc Surg 2013;145:1387-92)

Wound-healing impairment and wound infection after median sternotomy are important problems associated with increased morbidity and mortality. ${ }^{1,2}$ Excess costs arise primarily because of prolonged hospital stays and the need for repeated surgical procedures in these patients. ${ }^{3}$ Chronic obstructive pulmonary disease (COPD), smoking, diabetes, bilateral harvest of the internal thoracic artery, and, in particular, obesity have been identified as major risk factors. ${ }^{1,2,4,5}$

The breakdown of skin sutures with subsequent seepage of bacteria into the deeper layers has emerged as the key event in the development of the majority of wound infections after sternotomy, and Gram-positive bacteria are the most commonly isolated organisms in up to $80 \%$ of cases. ${ }^{1,6,7}$ This pathogenesis may explain why the risk of wound infections is especially elevated in obesity, because shear and traction forces on skin sutures are high

\footnotetext{
From the Department of Cardiothoracic and Vascular Surgery, Deutsches Herzzentrum Berlin, Berlin, Germany.

Disclosures: Authors have nothing to disclose with regard to commercial support.

Received for publication March 24, 2012; revisions received Aug 16, 2012; accepted for publication Sept 13, 2012; available ahead of print Oct 29, 2012.

Address for reprints: Onnen Grauhan, MD, PhD, MBA, Deutsches Herzzentrum Ber-

lin, Augustenburger Platz 1, 13353 Berlin (E-mail: grauhan@dhzb.de). $0022-5223 / \$ 36.00$

Copyright (C) 2013 by The American Association for Thoracic Surgery http://dx.doi.org/10.1016/j.jtcvs.2012.09.040
}

and colonization of skin folds with skin flora is ample. To prevent this kind of wound infection, diverse suture techniques and topical adhesives have been investigated in cardiac surgery. ${ }^{8-11}$

Placing a negative pressure wound dressing on clean skin immediately after suturing represents a new concept to reduce the likelihood of wound complications. The purpose of this study was to compare a new commercially available negative pressure wound therapy (NPWT) system (Prevena Incision Management System; KCI, San Antonio, Tex) and conventional sterile dry wound dressing in a high-risk group (ie, obese patients), with special regard to wound complications and infections. We hypothesized that NPWT for 6 to 7 days applied immediately after skin closure reduces the numbers of wound infections.

\section{MATERIALS AND METHODS}

In the period between April 1, 2010, and October 31, 2011, 163 patients with a body mass index of $30 \mathrm{~kg} / \mathrm{m}^{2}$ or more underwent operation at Deutsches Herzzentrum Berlin. Of these patients, 159 met the inclusion criteria, which were defined as follows: body mass index of $30 \mathrm{~kg} / \mathrm{m}^{2}$ or greater, age 18 years or more, legal competence, and absence of preoperative signs of inflammation. Exclusion criteria were defined as follows: immunologic disease, immunosuppressive therapy, (thoracic) skin disease, participation in another clinical study, and refusal of informed consent A total of 156 patients were enrolled and allocated to 2 study groups, alternating according to the time of operation. Patients with additional diabetes 


\section{Abbreviations and Acronyms \\ $\mathrm{COPD}=$ chronic obstructive pulmonary disease \\ $\mathrm{CI}=$ confidence interval \\ NPWT $=$ negative pressure wound therapy \\ $\mathrm{OR} \quad=$ odds ratio}

were allocated half and half to both groups, with priority. The primary end point of the study was the occurrence of wound infection within the 90-day follow-up period after surgery. The secondary end point was the occurrence of sterile wound complications, that is, dehiscence of skin or sternum. Informed consent to participate was obtained from each patient.

\section{Incision and Skin-Closure Techniques}

The skin of all patients was disinfected with $1 \%$ iodine in $50 \%$ alcohol (Braunoderm; Braun, Melsungen, Germany), and incision drapes were used. Antibiotic prophylaxis consisted of a preoperative injection of cefazolin, followed by a repeat dose after 8 and 16 hours. Skin and presternal soft tissue were incised by scalpel, and electrocautery was used cautiously. For sternum osteosynthesis, 7 to 8 single cerclages or 4 to 6 figures of 8 cerclages were used, and skin closure was performed with a monofilament absorbable suture (Biosyn 4-0; Syneture, Mansfield, Mass) by a meticulous intracutaneous running technique or with a monofilament nonabsorbable suture (Prolene 3-0; Ethicon, San Angelo, Tex) by the Donati technique depending on the surgeon's preference. Postoperatively, all patients wore an elastic thoracic bandage (Samco Clinhand, Mainburg, Germany). To minimize the risk of postoperative wound infections, postoperative hyperglycemia had been kept at less than $200 \mathrm{mg} / \mathrm{dL}$ by intensive perioperative glucose monitoring in all patients.

\section{Study Groups}

In the NPWT group $(n=75)$, the wound was covered with the foam dressing (Prevena Incision Management System) immediately after skin suturing and under sterile conditions. The suction pump was connected, and negative pressure of $-125 \mathrm{~mm} \mathrm{Hg}$ was applied. The foam dressing was removed after 6 to 7 days. In the controls (control group; $\mathrm{n}=75$ ), conventional wound dressings were changed for the first time on the first or second postoperative day. In both groups, wounds were inspected every 1 to 2 days thereafter.

\section{Definition of Risk Factors}

Diabetes, COPD, use of internal thoracic arteries, age, and gender were documented as additional risk factors. COPD was regarded as present if forced expiratory volume in 1 second was less than $80 \%$, and diabetes was documented if it was insulin-dependent or if diabetic-induced organ damage had already occurred.

\section{Wound Infections}

After removal of the primary wound dressing on day 6 or 7 in the NPWT group and after dressing removal on day 1 or 2 in the control group, all patients were examined daily up to the time of discharge for wound healing and signs of infection. Preoperatively, on postoperative days 1, 2, 4, and 7, and on the day before discharge, the leukocyte count and C-reactive protein were determined. If infection was suspected, these parameters also were measured on an ad hoc basis. To document infections after discharge, patients were contacted by phone 3 months postoperatively.

Superficial wound infections were defined on the basis of the criteria of the US Centers for Disease Control and Prevention: if there was microbiological evidence of microbes in the cutaneous or subcutaneous tissue at the site of the incision, if the incision was purposely reopened, or if at least one of the following secondary diagnoses was made: purulent secretion from the superficial incision with or without laboratory confirmation, positive bacterial culture from a fluid or tissue sample taken from the superficial incision under aseptic conditions, and at least 1 sign/symptom of infection: redness, heat, pain, or swelling. ${ }^{12,13}$ Deep wound infections were deemed present if there was a positive bacterial culture from mediastinal tissue or fluid, and a clinical picture of infection in the presence of one of the following: fever greater than $38^{\circ} \mathrm{C}$, purulent secretion from the wound, chest pain, sternal instability, or positive bacterial culture from the blood or mediastinal drainage fluid. In accordance with the criteria published by El Oakley and Wright, ${ }^{1}$ involvement of the sternum or cerclage wires was regarded as a criterion for deep wound infections.

\section{Statistical Analysis}

Qualitative data are presented as number (n) and percent. For quantitative data, median and quartiles were calculated. To compare study groups, the Mann-Whitney $U$ test and the Fisher exact test were used for dichotomous data. The odds ratio (OR) with a $95 \%$ confidence interval $(\mathrm{CI})$ was calculated. Freedom from infection was estimated by Kaplan-Meier analysis, and patient groups were compared by log-rank test. The data were processed and analyzed while preserving the patients' anonymity.

\section{RESULTS}

Six of 156 patients had to be excluded because of early rethoracotomy due to bleeding $(\mathrm{n}=3)$ and death unrelated to wound complications $(\mathrm{n}=3)$. A total of 150 of 159 $(94 \%)$ of the screened patients were included in the study analysis after the end of the follow-up period. In each group, all 75 patients could be followed for at least 90 days. NPWT was well tolerated in all patients. In 2 patients, the foam dressing had to be readjusted because of air leakage after 3 and 4 days, respectively. Preoperative patient characteristics, comorbidities, and procedure-related variables were comparable between the NPWT group and control group (Table 1).

\section{Wound Infections and Sterile Complications}

Three of 75 patients (4\%) with NPWT (NPWT group) and 12 of 75 patients $(16 \%)$ with conventional dressing (control group) had wound infections $(P=.0266$; OR, 4.57; 95\% CI, 1.23-16.94) (Table 2). Gram-positive skin flora was found in only 1 wound swab in the NPWT group but in 10 wound swaps in the control group $(P=.0090$; OR, 11.39 ; $95 \%$ CI, 1.42-91.36), whereas 2 of 3 wound infections in the NPWT group and 2 wound infections in the control group were deep infections caused by contamination with Gram-negative bacteria (Table 2). Superficial wound infections had to be treated by debridement and secondary wound closure in 5 cases (including the case in the NPWT group) and by repeated revisions, including vacuumassisted closure therapy, in the remaining 4 cases.

Sternum dehiscence was found in 1 patient in the NPWT group and in 3 patients in the control group $(P=.6199)$. However, all 3 patients in the control group had additional sternum osteomyelitis caused by skin flora requiring therapy for weeks, whereas the single patient in the NPWT group had a sterile sternum with completely healed skin 
TABLE 1. Patient characteristics, comorbidities, and procedure-related variables

\begin{tabular}{|c|c|c|c|c|}
\hline & NPWT & Control & Total & $P$ value \\
\hline \multicolumn{5}{|l|}{ Preoperative } \\
\hline Men (\%) & $26(35 \%)$ & $32(43 \%)$ & $58(39 \%)$ & .4019 \\
\hline Age, y & $68(44-84)$ & $67(54-81)$ & $68(44-81)$ & .5934 \\
\hline BMI & $37(30-62)$ & $36(30-45)$ & $37(30-62)$ & .2192 \\
\hline COPD $(\%)$ & $15(20 \%)$ & $22(29 \%)$ & $37(25 \%)$ & .2556 \\
\hline Diabetes mellitus (\%) & $41(55 \%)$ & $40(53 \%)$ & $81(54 \%)$ & .9999 \\
\hline LVEF $<30 \%$ & $8(11 \%)$ & $5(7 \%)$ & $13(9 \%)$ & .5632 \\
\hline Reoperation (\%) & $3(4 \%)$ & $5(7 \%)$ & $8(5 \%)$ & .7189 \\
\hline \multicolumn{5}{|l|}{ Intraoperative } \\
\hline \multicolumn{5}{|l|}{ Type of procedure } \\
\hline CABG + LITA & $30(40 \%)$ & $40(53 \%)$ & $70(47 \%)$ & .1405 \\
\hline CABG - LITA & $2(3 \%)$ & $1(1 \%)$ & $3(4 \%)$ & 1.0 \\
\hline $\mathrm{CABG}+\mathrm{BITA}$ & $0(0 \%)$ & $0(0 \%)$ & $0(0 \%)$ & 1.0 \\
\hline Valve & $27(36 \%)$ & $22(29 \%)$ & $49(33 \%)$ & .4864 \\
\hline Double valve & $5(7 \%)$ & $3(4 \%)$ & $8(5 \%)$ & .7189 \\
\hline Combination & $7(9 \%)$ & $8(11 \%)$ & $15(10 \%)$ & .9999 \\
\hline other & $3(4 \%)$ & $1(1 \%)$ & $4(3 \%)$ & 6199 \\
\hline \multicolumn{5}{|l|}{ Sternal closure } \\
\hline$>6$ conventional & $64(85 \%)$ & $55(73 \%)$ & $118(79 \%)$ & .1057 \\
\hline Figures of 8 & $11(15 \%)$ & $20(27 \%)$ & $32(21 \%)$ & .1057 \\
\hline \multicolumn{5}{|l|}{ Skin suture } \\
\hline Intracutaneous & $42(56 \%)$ & $37(49 \%)$ & $79(53 \%)$ & .5131 \\
\hline Donati & $33(44 \%)$ & $38(51 \%)$ & $71(47 \%)$ & .5131 \\
\hline \multicolumn{5}{|l|}{ Postoperative } \\
\hline$>3$ units $\mathrm{PRBC}$ & $1(1 \%)$ & $3(4 \%)$ & $4(30 \%)$ & .6199 \\
\hline Shock (hemodynamically unstable condition or shock) & $2(3 \%)$ & $1(1 \%)$ & $7(5 \%)$ & 1.0 \\
\hline Renal failure & $1(1 \%)$ & $3(4 \%)$ & $8(5 \%)$ & .6199 \\
\hline
\end{tabular}

$N P W T$, Negative pressure wound therapy; $B M I$, body mass index; $C O P D$, chronic obstructive pulmonary disease; $L V E F$, left ventricular ejection fraction; $C A B G$, coronary artery bypass grafting; LITA, left internal thoracic artery; BITA, bilateral internal thoracic artery; PRBC, packed red blood cell.

and could be treated by sterile re-osteosynthesis. In each group, 1 further patient had a sterile skin dehiscence without infection (Table 3).

\section{DISCUSSION}

\section{Poststernotomy Wound Infections}

Several aspects have been discussed about the pathogenesis of wound infections after sternotomy. ${ }^{1,2,4,5,7,14}$ In an excellent analysis of 126 cases of postoperative mediastinitis at Karolinska Hospital, Sweden, Gårdlund and colleagues ${ }^{6}$ distinguished mediastinitis associated with obesity and sternal dehiscence, and often caused by coagulase-negative staphylococci (type 1), mediastinitis after perioperative contamination of the mediastinal space, often caused by Staphylococcus aureus (type 2), and mediastinitis caused by spread from concomitant infections in the postoperative period (type 3 ).

In view of its pathogenesis, type 1 mediastinitis has to be regarded as the end point of the clinical spectrum of poststernotomy wound complications that ranges from sterile skin breakdown to mediastinitis caused by skin flora. ${ }^{1,6,15}$ Therefore, the prevention of skin breakdown would mean prevention of the majority of poststernotomy complications. ${ }^{15}$

\section{Wound Closure in Obesity}

From a mechanical point of view, skin incision after median sternotomy in obesity has 2 problematic aspects: (1) In the sitting position, the skin suture is bent in the inframammary fold and the skin edges are forced apart, and this in an area of sprawling skin flora and often intertriginous problems (Figures 1 and 2). (2) In the supine position, the weight of fat tissue pulls apart the skin edges to both sides and this represents a problem, especially in the case of heavy breasts. ${ }^{16}$ By taking all these aspects into account, skin closure, especially in obesity, should provide for (1) resistance to mechanical tractive forces, (2) undisturbed blood supply at the skin edges to ensure the wound healing process, and (3) an immediate barrier to seepage of skin flora.

\section{Concept of Prophylactic Negative Pressure Wound Therapy}

NPWT is an experimentally and clinically proven concept to treat poststernotomy infection with the benefits of wound secretion drainage, improved microcirculation, and the promotion of (granulation) tissue proliferation. ${ }^{17}$ Atkins and colleagues ${ }^{18}$ recently showed that prophylactic NPWT over clean and closed sternal incisions may reduce 
TABLE 2. Wound infections

\begin{tabular}{|c|c|c|c|c|c|c|c|c|c|}
\hline \multirow[b]{2}{*}{ Patient no. } & \multirow[b]{2}{*}{ Age, $y$} & \multirow[b]{2}{*}{ Gender } & \multirow[b]{2}{*}{ Operation } & \multirow[b]{2}{*}{ BMI } & \multirow[b]{2}{*}{ Diabetes } & \multirow[b]{2}{*}{ Time } & \multicolumn{3}{|c|}{ Wound infection } \\
\hline & & & & & & & Mode & Microbiological swabs & Sternum \\
\hline \multicolumn{10}{|c|}{ NPWT group } \\
\hline 1 & 65 & M & $\mathrm{C} / \mathrm{L}$ & 44 & + & RoN & PSA & 1 & \\
\hline 2 & 60 & M & $\mathrm{C} / \mathrm{L}$ & 32 & & RoN & DWI & $2,3,4$ & Stable \\
\hline 3 & 62 & $\mathrm{~F}$ & AVR & 34 & + & RoN & SWI & 5 & \\
\hline \multicolumn{10}{|c|}{ Control group } \\
\hline 4 & 59 & M & $\mathrm{rC}$ & 39 & + & 6 & SWI & 5 & \\
\hline 5 & 64 & $\mathrm{~F}$ & $\mathrm{C} / \mathrm{L}$ & 44 & + & 12 & SWI & 5,6 & \\
\hline 6 & 55 & M & $\mathrm{C} / \mathrm{L}$ & 38 & & 10 & DWI & 5 & Dehiscent \\
\hline 7 & 69 & $\mathrm{~F}$ & AVR & 33 & & 11 & DWI & 5 & Dehiscent \\
\hline 8 & 72 & M & $\mathrm{C} / \mathrm{L}$ & 38 & + & 8 & SWI & 6 & \\
\hline 9 & 67 & $\mathrm{~F}$ & $\mathrm{C} / \mathrm{L}$ & 36 & & 7 & SWI & 5,6 & \\
\hline 10 & 66 & $\mathrm{~F}$ & $\mathrm{C} / \mathrm{L}$ & 33 & + & 13 & SWI & 5 & \\
\hline 11 & 67 & $\mathrm{~F}$ & $\mathrm{C} / \mathrm{L}$ & 36 & & 16 & SWI & 3,7 & \\
\hline 12 & 66 & $\mathrm{~F}$ & $\mathrm{C} / \mathrm{L}$ & 45 & + & 10 & SWI & 5 & \\
\hline 13 & 54 & $\mathrm{~F}$ & $\mathrm{C} / \mathrm{L}$ & 37 & + & 35 & DWI & 5 & Dehiscent \\
\hline 14 & 58 & M & $\mathrm{C} / \mathrm{L}$ & 36 & & 6 & SWI & 5,6 & \\
\hline 15 & 79 & $\mathrm{~F}$ & AVR & 39 & & 22 & DWI & 3,4 & Stable \\
\hline
\end{tabular}

$1=$ Escherichia coli $; 2=$ Staphylococcus aureus $; 3=$ Klebsiella pneumoniae $; 4=$ Enterobacter cloacae $; 5=$ Staphylococcus epidermidis $; 6=$ Staphyloccocus hemolyticus; 7 = Pseudomonas. BMI, Body mass index; NPWT, negative pressure wound therapy; C/L, coronary artery bypass graft with left internal thoracic artery; AVR, aortic valve replacement; $r C$, redo coronary artery bypass graft; RoN, diagnosed at Removal of NPWT dressing; $P S A$, pre-sternal abscess; $D W I$, deep wound infection; $S W I$, superficial wound infection.

the likelihood of postoperative wound complications. In the sterile environment underneath the dressing, incision edges were held together, wound secretions were drained, and improved skin microcirculation supported wound healing. ${ }^{18-21}$ As mentioned previously, these effects are especially important in primary wound healing in obese patients.

\section{Impact of Prophylactic Negative Pressure Wound Therapy on Wound Infection}

The overall prevalence of deep sternal wound infection after median sternotomy varies from $0.4 \%$ to $5 \%$, and the average prevalence in recent reports has approached $1 \%$, whereas superficial wound infections were found in $7.7 \% .^{7,22}$ Therefore, our infection rates of $6.0 \%$ for superficial infections and $4.0 \%$ for deep infections in all 150 patients or even $10.7 \%$ for superficial infections and $5.3 \%$ for deep infections in the control group seem high. However, these were observed in a high-risk group of obese patients. It is striking that 11 of 15 wound infections were assigned to type 1 according to the classification by
Gårdlund and colleagues, ${ }^{6}$ and, as mentioned previously, obesity is associated with this type of wound infection.

With conventional sterile wound dressing, 12 of 75 patients $(16 \%)$ had post-sternotomy wound infection (control group), but this was the case in only 3 of 75 patients (4\%) with continuous NPWT (NPWT group) $(P=.0266$; OR, 4.57 ; $95 \% \mathrm{CI}, 1.23-16.94)$. By considering only wound infection by Gram-positive skin flora, infections were found in only 1 patient in the NPWT group compared with 10 patients in the control group $(P=.0090$; OR, $11.39 ; 95 \% \mathrm{CI}$, 1.42-91.36), indicating a considerable impact of prophylactic NPWT.

When the foam dressing was removed after 6 to 7 days in the NPWT group, the incision was primarily closed in 71 of 75 patients (95\%) (Figure 2). Not a single wound infection occurred during the further course, indicating that wound closure already represents a sufficient barrier to external infectious sources (Figure 3). Thus, the key event of most infectious complications, that is, skin breakdown and subsequent seepage of skin flora into deeper layers, can be prevented in most cases by prophylactic NPWT. ${ }^{1,6}$ In

TABLE 3. Sterile wound complications

\begin{tabular}{|c|c|c|c|c|c|c|c|}
\hline Patient no. & Age, $\mathbf{y}$ & Gender & Operation & BMI & Diabetes & Time & Sterile wound complications \\
\hline \multicolumn{8}{|c|}{ NPWT group } \\
\hline 16 & 54 & $\mathrm{~F}$ & CABG & 62 & & 32 & Sternum dehiscence, skin closed \\
\hline 17 & 72 & $\mathrm{~F}$ & CABG/LITA & 38 & + & RoN & Skin dehiscence, sternum stable \\
\hline \multicolumn{8}{|c|}{ Control group } \\
\hline 18 & 67 & $\mathrm{~F}$ & AVR & 37 & & 19 & Skin dehiscence, sternum stable \\
\hline
\end{tabular}

BMI, Body mass index; NPWT, negative pressure wound therapy; $C A B G$, coronary artery bypass grafting; LITA, left internal thoracic artery; $A V R$, aortic valve replacement; RoN, diagnosed at Removal of NPWT dressing. 


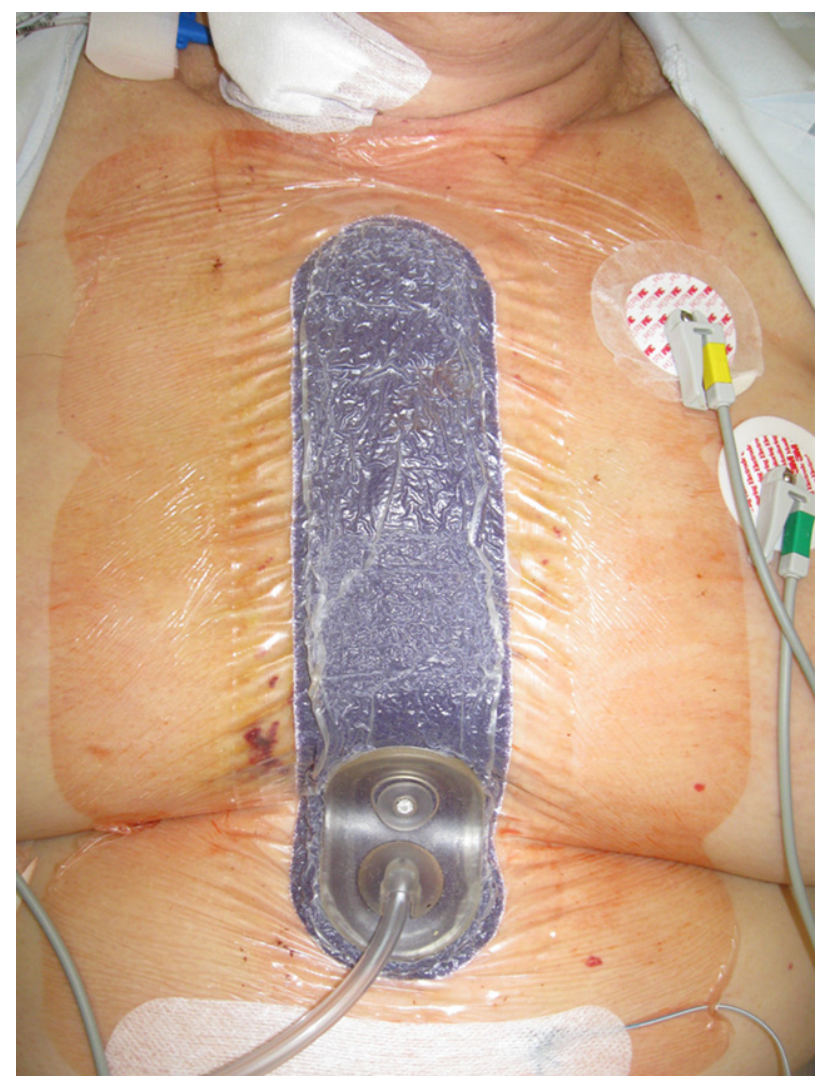

FIGURE 1. Sitting patient with NPWT foam dressing: The incision is bent in the inframammary fold, provoking traction forces that would pull apart skin edges. However, NPWT dressing conforms to body contours and helps to hold incision edges together.

contrast, in the control group, 9 of 12 wound infections $(75 \%)$ occurred beyond the first postoperative week and up to postoperative day 35 (Figure 3). This indicates that with conventional wound dressing (control group) an adequate barrier to external infectious sources is established considerably later, which in turn may underline the positive impact of wound secretion drainage (hematoma, seroma) and the improved microcirculation on the course of wound healing observed with NPWT in previous studies. ${ }^{19-21}$

Two of 3 wound infections in the NPWT group (patients 1 and 2) and 2 of 12 wound infections in the control group (patients 11 and 15) were infections caused by contamination with Gram-negative bacteria (Table 2). In regard to the time point of infection, contamination had probably already occurred during the operation in patients 1 and 2 , that is, these infections should not be regarded as due to "NPWT failure." On the other hand, in patients 11 and 15 with conventional dressing (control group) and wound infection on postoperative day 16 and 22, respectively, contamination had probably occurred during the postoperative course, indicating a still insufficient barrier to external infectious sources (Table 2).

At removal of the NPWT foam dressing on postoperative day 7 in patient 1 , the incision was closed, but the skin

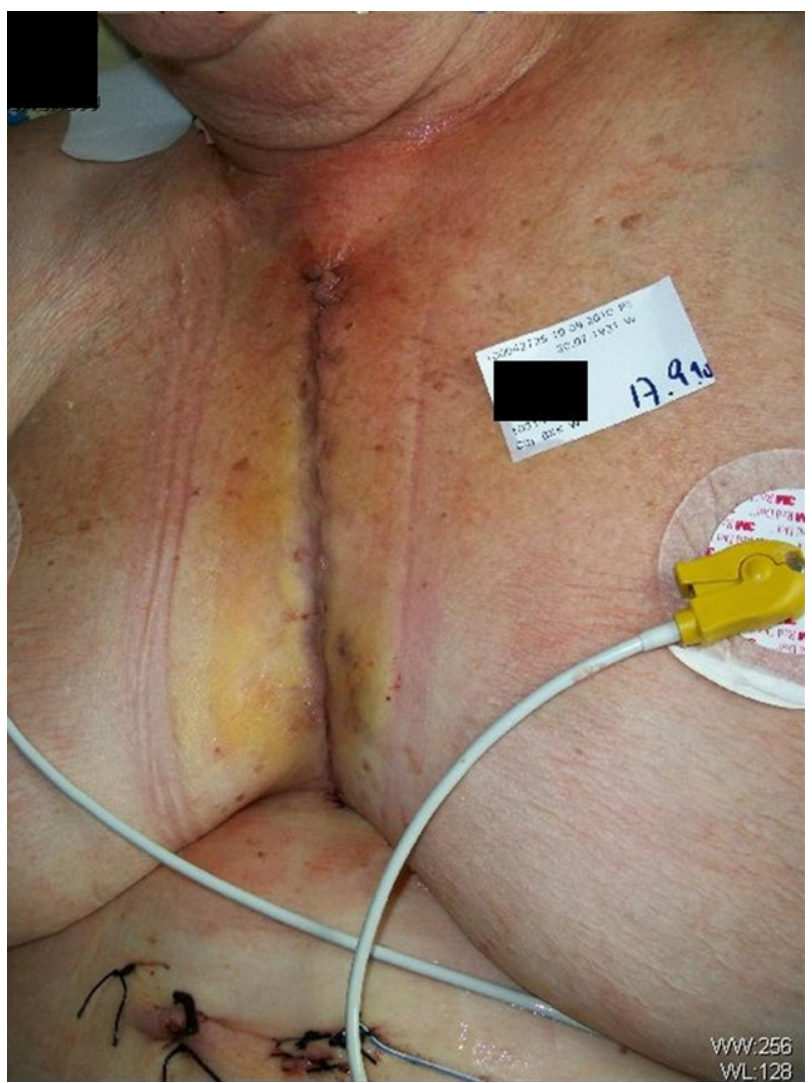

FIGURE 2. Skin incision at removal of foam dressing on postoperative day 6. Despite difficult conditions (bending skin in inframammary fold, skin perspiration, and insulin-dependent diabetes), wound healing was primary and already represents a sufficient barrier to external infectious sources.

showed signs of inflammation due to an Escherichia coli abscess located $1 \mathrm{~cm}$ underneath. This may illustrate possible concerns that with NPWT dressing the skin incision cannot be inspected for the first 6 to 7 postoperative days.

\section{Impact of Prophylactic Negative Pressure Wound Therapy on Sterile Wound Complications}

One patient in each group had sterile wound dehiscence (patients 17 and 18) probably because of inappropriate use of electrocautery, resulting in skin necrosis followed by dehiscence.

It has been discussed whether sternal dehiscence has to be regarded as an effect or a cause of wound infection. However, there is a consensus that the bone and wires have to be covered by closure of the fascia and muscle after sternum osteosynthesis. As reported by Francel and Kouchoukos, ${ }^{15}$ infection after sternotomy remains superficial in most cases because the soft tissue layer of closure over the sternum is maintained. These data suggest that skin breakdown and seepage of skin flora cause most sternum infections independently of whether the sternum at this time point is still stable or it is already dehiscent and thereby may cause or facilitate incision breakdown. 


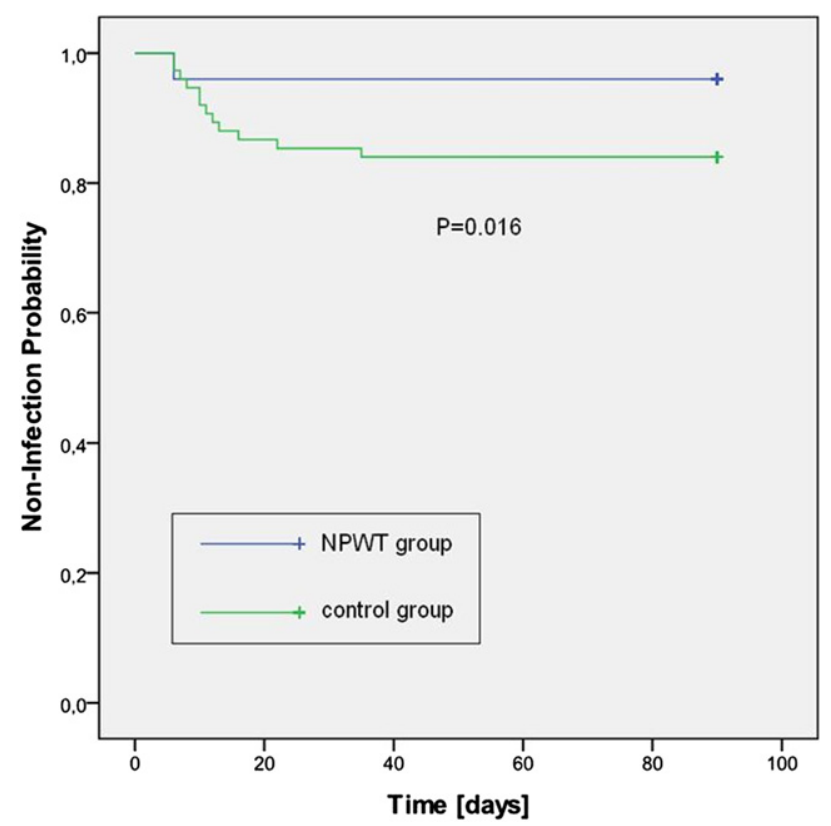

FIGURE 3. Kaplan-Meier analysis of (superficial and deep) wound infections after median sternotomy in obese patients (see text). NPWT, Negative pressure wound therapy.

In this study, 1 patient in the NPWT group and 3 patients in the control group had sternum dehiscence. In patient 1 (NPWT group), the skin incision was closed after 7 days of NPWT, but sternum dehiscence was diagnosed after 3 weeks and sterile re-osteosynthesis could be performed. In contrast, in the control group, 3 of 12 wound infections (patients 6, 7, and 13) showed sternal bone involvement and skin flora as causative (Table 2). One may surmise that these 3 infections could have been prevented by prophylactic NPWT.

\section{CONCLUSIONS}

Negative pressure wound therapy over clean, closed incisions for the first 6 to 7 postoperative days reduces the likelihood of postoperative wound infection after median sternotomy in a high-risk group of obese patients.

The authors thank Anne Gale for editorial assistance.

\section{References}

1. El Oakley RM, Wright JE. Postoperative mediastinitis: classification and management. Ann Thorac Surg. 1996;61:1030-6.

2. Gelape CL. Surgical wound infection following heart surgery. Arq Bras Cardiol. 2007;89:e3-9.
3. Graf K, Ott E, Vonberg RP, Kuehn C, Haverich A, Chaberny IF. Economic aspects of deep sternal wound infections. Eur J Cardiothorac Surg. 2010;37:893-6.

4. Olsen MA, Lock-Buckley P, Hopkins D, Polish LB, Sundt TM, Fraser VJ. The risk factors for deep and superficial chest surgical-site infections after coronary artery bypass graft surgery are different. J Thorac Cardiovasc Surg. 2002;124: 136-41.

5. Molina JE, Lew RS, Hyland KJ. Postoperative sternal dehiscence in obese patients: incidence and prevention. Ann Thorac Surg. 2004;78:912-7.

6. Gårdlund B, Bitkover CY, Vaage J. Postoperative mediastinitis in cardiac surgery-microbiology and pathogenesis. Eur J Cardiothorac Surg. 2002;21: 825-30.

7. Durham S Ji, Gold J Pi. Late complications of cardiac surgery. In: Cohn LH, ed. Cardiac Surgery in the Adult. 3rd ed. New York, NY: McGraw-Hill; 2008. $535-48$.

8. Karabay O, Fermanci E, Silistreli E, Aykut K, Yurekli I, Catalyurek H, et al. Intracutaneous versus transcutaneous suture techniques: comparison of sternal wound infection rates in open-heart surgery patients. Tex Heart Inst J. 2005; 32:277-82.

9. Risnes I, Abdelnoor M, Lundblad R, Baksaas ST, Svennevig JL. Sternal wound infections in patients undergoing open-heart surgery: randomized study comparing intracutaneous and transcutaneous suture techniques. Ann Thorac Surg. 2001;72:1587-91.

10. Souza EC, Fitaroni RB, Januzelli DM, Macruz HM, Camacho JC, Souza MR. Use of 2-octyl cyanoacrylate for skin closure of sternal incisions in cardiac surgery: observations of microbial barrier effects. Curr Med Res Opin. 2008;24: 151-5.

11. Grauhan O, Navasardyan A, Hofmann M, Müller P, Hummel M, Hetzer R. Cyanoacrylate-sealed Donati suture for wound closure after cardiac surgery in obese patients. Interact Cardiovasc Thorac Surg. 2010;11:763-7.

12. Mangram AJ, Horan TC, Pearson ML, Silver LC, Jarvis WR. Guidelines for prevention of surgical site infection (CDC). Infect Control Hosp Epidemiol. 1999; 20:247-78.

13. Teebken OE, Bisdas T, Assadian O, Ricco JB. Recommendations for reporting treatment of aortic graft infections. Eur J Vasc Endovasc Surg. 2012;43: 174-81.

14. Grossi EA, Culliford AT, Krieger KH, Kloth D, Press R, Baumann FG, et al. A survey of 77 major infectious complications of median sternotomy: a review of 7,949 consecutive operative procedures. Ann Thorac Surg. 1985;40:214-23.

15. Francel TJ, Kouchoukos NT. A rational approach to wound difficulties after sternotomy: the problem. Ann Thorac Surg. 2001;72:1411-8.

16. Copeland M, Senkowski C, Ergin MA, Landsman S. Macromastia as a factor in sternal wound dehiscence following cardiac surgery: management combining chest wall reconstruction and reduction mammoplasty. J Cardiac Surg. 1992;7: 275-8.

17. Doss M, Martens S, Wood JP, Wolff JD, Baier C, Moritz A. Vacuum-assisted suction drainage versus conventional treatment in the management of poststernotomy osteomyelitis. Eur J Cardiothorac Surg. 2002;22:934-8.

18. Atkins BZ, Wooten MK, Kistler J, Hurley K, Hughes GC, Wolfe WG. Does negative pressure wound therapy have a role in preventing poststernotomy wound complications? Surg Innov. 2009;16:140-6.

19. Pachowsky M, Gusinde J, Klein A, Lehrl S, Schulz-Drost S, Schlechtweg P, et al. Negative pressure wound therapy to prevent seromas and treat surgical incisions after total hip arthroplasty. Int Orthop. 2012;36:719-22.

20. Stannard JP, Atkins BZ, O'Malley D, Singh H, Bernstein B, Fahey M, et al. Use of negative pressure therapy on closed surgical incisions: a case series. Ostomy Wound Manage. 2009;55:58-66.

21. Stannard JP, Robinson JT, Anderson ER, McGwin G Jr, Volgas DA, Alonso JE. Negative pressure wound therapy to treat hematomas and surgical incisions following high-energy trauma. J Trauma. 2006;60:1301-6.

22. Jonkers D, Elenbaas T, Terporten P, Nieman F, Stobberingh E. Prevalence of 90-days postoperative wound infections after cardiac surgery. Eur J Cardiothorac Surg. 2003;23:97-102. 